\title{
Outcomes and hospital costs associated with the Norwood operation: beyond morbidity and mortality - CORRIGENDUM
}

Brian E. Kogon, Kirk Kanter, Bahaaldin Alsoufi, Kevin Maher, Matthew E. Oster

doi:10.1017/S1047951114002224, Published by Cambridge University Press, 3 November 2014.

First published online: 4 December 2014

This paper contains an error in Table 4. The authors apologise for this error.

In the last row of the Table, it states:

Reimbursement (charges/collections) $=46 \%$

It should actually be:

Reimbursement (collections/ charges) $=46 \%$

\section{Reference}

Kogon BE, Kanter K, Alsoufi B, Maher K, Oster ME. Outcomes and hospital costs associated with the Norwood operation: beyond morbidity and mortality. Cardiol Young. Published by Cambridge University Press, 3 November 2014. doi:10.1017/S1047951114002224. 